\title{
Honoris Causa concedido ao Prof. J. Marcovitch
}

\section{Pelo sr. Yves Bouchut, professor da Faculdade de Ciências Econômicas e Administrativas - Université Lumiére}

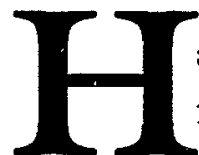

á dois anos, ao conceder ao seu compatriota, Jorge Amado, o diploma de Doutor Honoris Causa, nossa Universidade reconhecia, através de sua pessoa e de sua obra, a importância da literatura brasileira, e destacava o caráter universal desse escritor que tão bem soube expressar as tradiçōes populares de seu país.

Hoje, ao recebê-lo aqui, a Université Lumière presta homenagem a um reconhecido representante da administraçáo tecnológica, a um humanista científico, figura da nova modernidade brasileira, para a qual tanto contribui, e a um amigo muito fiel de nossa regiäo, de nossa cidade e de nossa Universidade.

Esta cerimônia ocorre sob o signo do Bicentenário da Revolução Francesa e tal contexto, creio eu, náo é algo que lhe desagrade. Na realidade, em comum com a maioria dos homens surgidos no Século das Luzes e que fizeram 1789, o senhor defende um ideal de progresso e abertura, um ideal de ciência, um ideal de açáo. Estas são as numerosas qualidade que me permitirão, caro amigo, delinear o seu retrato.

O senhor é um homem de progresso: permanentemente à escuta de seu tempo, curioso de todas as coisas, consciente de vivenciar as primícias de uma revoluçáo da ciência e da técnica. O progresso científico e técnico tornaram-se as chaves de sua reflexáo. O senhor encarna, assim, este novo pensamento econômico que, longe de limitar-se a uma simples análise das condiçóes do subdesenvolvimento, tenta, de maneira constante, obter soluçōes, enfatizando a maneira pela qual as mudanças tecnológicas em curso podem levar um país à posiçăo de Novo País Industrializado, condiçăo a que o Brasil, graças a homens como o senhor, chega em nossos dias.

Esta constante curiosidade, em relação a um futuro de progresso, é acompanhada por um grande espírito de abertura para o mundo e de acolhimento e atenção aos demais. Seu espírito de abertura é bem conhecido de todos quantos o conhecem; permita-me relembrar os 
cafés da manhã que compartilhamos por ocasiāo de suas estadas anteriores em Lyon. Quantos intercâmbios apaixonantes sobre a evolução econômica e política da França, soḅre o futuro da Europa, que ocupa posiçáo de destaque em suas preocupaçōes, sobre as relaçóes com a América Latina!

Esta mesma abertura reflete-se também na maneira pela qual o senhor dirige o Instituto de Estudos Avançados da Universidade de São Paulo. Este instituto tornou-se, em nível brasileiro, um local de discussōes e confrontos. Graças a sua orientação, reúnem-se ali, por exemplo, parlamentares ou especialistas brasileiros que discutem os problemas ligados ao progresso técnico, ou mesmo participantes de um grande colóquio internacional sobre a Revoluçáo Francesa, tal como o recentemente ali organizado, ou ainda membros de um seminário sobre as condiçóes e paradoxos de uma nova sociedade.

Finalmente, este mesmo espírito de abertura se manifesta na verdadeira paixão com a qual o senhor se dedica à leitura assídua de numerosos jornais e revistas. Também na qualidade de articulista, o senhor se faz presente em numerosos periódicos, e suas contribuiçóes regulares à prestigiosa Folba de $S$. Paulo chamam freqüentemente a atenção de seus leitores.

Mas este espírito de progresso e abertura possui como contrapartida o aspecto de homem de ciểncia, e seriam múltiplos os elementos de sua carreira que eu poderia aqui evocar.

Professor titular da Faculdade de Economia e Administraçáo da Universidade de São Paulo, da qual o senhor já foi diretor, incluem-se em seu currículo numerosas publicaçóes científicas, uma participaçáo assídua em seminários e conferências nacionais e internacionais, que contribuíram, todas elas, para situar a importância da inovação, da tecnologia e da ciência a serviço de uma política de desenvolvimento. Toda a sua obra contribui para demonstrar que uma política de inovaçăo industrial conseqüente năo pode ser concebida sem uma política para a tecnologia. Surge aqui uma constante em torno da qual, pouco a pouco, constituiu-se um sólido pensamento científico.

Sua intensa atividade de pesquisa náo o leva, no entanto, a negligenciar a atividade, igualmente importante, de ensino $e$ orientaçáo dos estudantes. Mais uma vez, o senhor sabe encontrar a disponibilidade necessária e, acima de tudo, conquistar o respeito e o amor de seus alunos, a cujo alcance o senhor sempre soube colocar-se: associando, ao rigor e disciplina do pensamento científico que apregoa, toda a simplicidade do pedagogo. Sua orientaçáo atenta de numerosos trabalhos de doutorandos contribui para a formaçáo de especialistas na área da política e administração da tecnologia, atendendo às necessidades de seu país. O senhor pertence, portanto, ao grupo daqueles que participam, direta e ativamente; na construçáo do Brasil de amanhă.

Na realidade, toda esta atividade cientifica seria pelo senhor vista como inacabada, se não se fizesse acompanhar de uma presença ativa no campo. Homem de açáo, o senhor o é, uma vez que a ciência econômica jamais permaneceu, em seu ponto de vista, na condiçăo de simples objeto de especulaçăo teórica. Sua concepção de progresso, sua 
visão do futuro sempre o levaram a vincular estreitamente a prática teórica à prática concreta. Numerosos são os momentos de sua vida que testemunham este vínculo, levando-o a assumir a posiçăo de consultor junto a numerosas instituiçóes internacionais (Onudi, Unesco, Cepal) diretamente envolvidas no estabelecimento de políticas de desenvolvimento.

Em 1986 e 1987, coube-lhe presidir sobre o destino da Companhia de Energia do Estado de São Paulo, provando desta forma que, em seu ponto de vista, as relaçóes entre a universidade e a indústria podem ser reais.

Coube-lhe também presidir ou coordenar diferentes programas de pesquisa, que contribuíram para a orientaçáo do progresso científico e tecnológico do Brasil; e é de meu conhecimento o seu profundo envolvimento pessoal na política brasileira de pesquisa e desenvolvimento.

Enfim, juntamente com alguns colegas sul-americanos, no seio do que eu chamaria de Colégio invisível, o senhor se dedica a uma reflexão permanente acerca dos problemas do domínio tecnológico. Esta atividade o torna conhecido entre os responsáveis pela tomada de decisóes, entre os industriais e entre a comunidade universitária: todos têm perfeita consciência do papel pelo senhor desempenhado no continente americano, como pioneiro da administração aplicada ao desenvolvimento tecnológico.

Ultrapassando, assim, os limites do Brasil, sua competência, sua atividade e sua presença se estendem sobre todo um conjunto de países e suas recomendaçóes encontram, em geral, uma escuta atenta, em funçáo do senso de diplomacia e moderação que acompanham a enorme força de conviç̧ão capaz de convencer até os mais reticentes.

Diferentes honrarias, tanto nacionais quanto internacionais, já vieram recompensar suas atividades. Mesmo o seu país acaba, há alguns dias, de reconhecer a importância de seus trabalhos e compromissos. $\mathrm{Na}$ realidade, o senhor acaba de receber o Prêmio Moinho Santista, que equivale, no Brasil, ao nosso prêmio da Académie des Sciences Morales et Politiques. Em nome de todos os presentes, desejo congratulá-lo por este novo testemunho de honra que lhe foi conferido.

Finalmente, permitam-me encerrar este retrato, acrescentando-lhe um toque um pouco mais pessoal. Todas estas múltiplas ocupaçóes náo o impedem de ser ao mesmo tempo um grande apreciador da. literatura $e$ do cinema. Qualquer que seja, ainda, a importância e o peso de suas atividades, existe sempre um tempo para dedicar-se totalmente à família, e sua esposa, Shirley, que pôde juntar-se a nós por ocasião desta cerimônia, confiava-me ainda há pouco, e permitam-me citá-la, que o senhor é "um pai de família e um marido maravilhoso". Eu sei que ela tem pelo senhor uma profunda admiração; permita-nos, pois, caro Jacques, o prazer de partilhar com ela este sentimento, dizendo-lhe o quanto nossa Universidade se sente feliz ao conferir-lhe hoje este título de Doutor Honoris Causa. 


\section{Resposta do professor Marcovitch}

Senhor presidente

Senhor chanceler

Meu caro colega e amigo Yves Bouchut

Senhoras e senhores

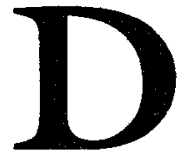

irijo-me, inicialmente, a meu colega e amigo, professor Yves Bouchut, homem totalmente voltado ao ensino, à pesquisa e à cultura, que acaba de demonstrar, mais uma vez, sua imensa generosidade em relação a $\operatorname{mim}$.

Faço questão de agradecer à Universidade Lumière-Lyon 2, na pessoa de seu presidente, sr. Michel Cusin. Confesso-lhe, senhor presidente, que sentimentos de surpresa, emoção e alegria tomaram conta de mim, enquanto lia sua carta de 22 de fevereiro. Esta carta me anunciava a proposta da Faculdade de Ciências Econômicas e Administrativas e a decisão do Conselho Universitário de conceder-me o título de Doutor Honoris Causa nesta prestigiosa instituição acadêmica.

Surpresa, porque muitos de meus projetos de pesquisa e ação, embora já tenham levado a resultados muito frutíferos, encontram-se ainda em curso de realização.

Emoção, pelo fato de meus colegas de Lyon 2 se terem recordado de um trabalho comum, realizado em Sáo Paulo, centro econômico de uma América Latina tão longínqua.

Alegria, por ter a oportunidade de rever, em um ambiente festivo, os meus amigos de Lyon 2, da Associação Rhône-Alpes-Brasil, do Espaço Bellecour e da Societé Lyonnaise de Banque.

Como sabe, senhor presidente, elos muito estreitos unem nossas regióes e nossas universidades. Desde a primeira visita da sra. Simone Saillard a São Paulo, nossas universidades vêm organizando esforços conjuntos nas áreas de línguas, literatura, economia e administraçăo. Além disso, as relaçóes estabelecidas entre a regiáo Ródano-Alpes e o Brasil oferecem uma importante e sólida plataforma para a colaboração, como já o demonstraram várias missóes de dirigentes de empresas, bem como a reflexão conjunta sobre as relaçōes Norte-Sul na área da saúde.

Desde 1980 , a pesquisa sobre mudanças tecnológicas e sobre a administraçẫo da inovaçáo tornou-se prioritária $\mathrm{em}$ nossas 


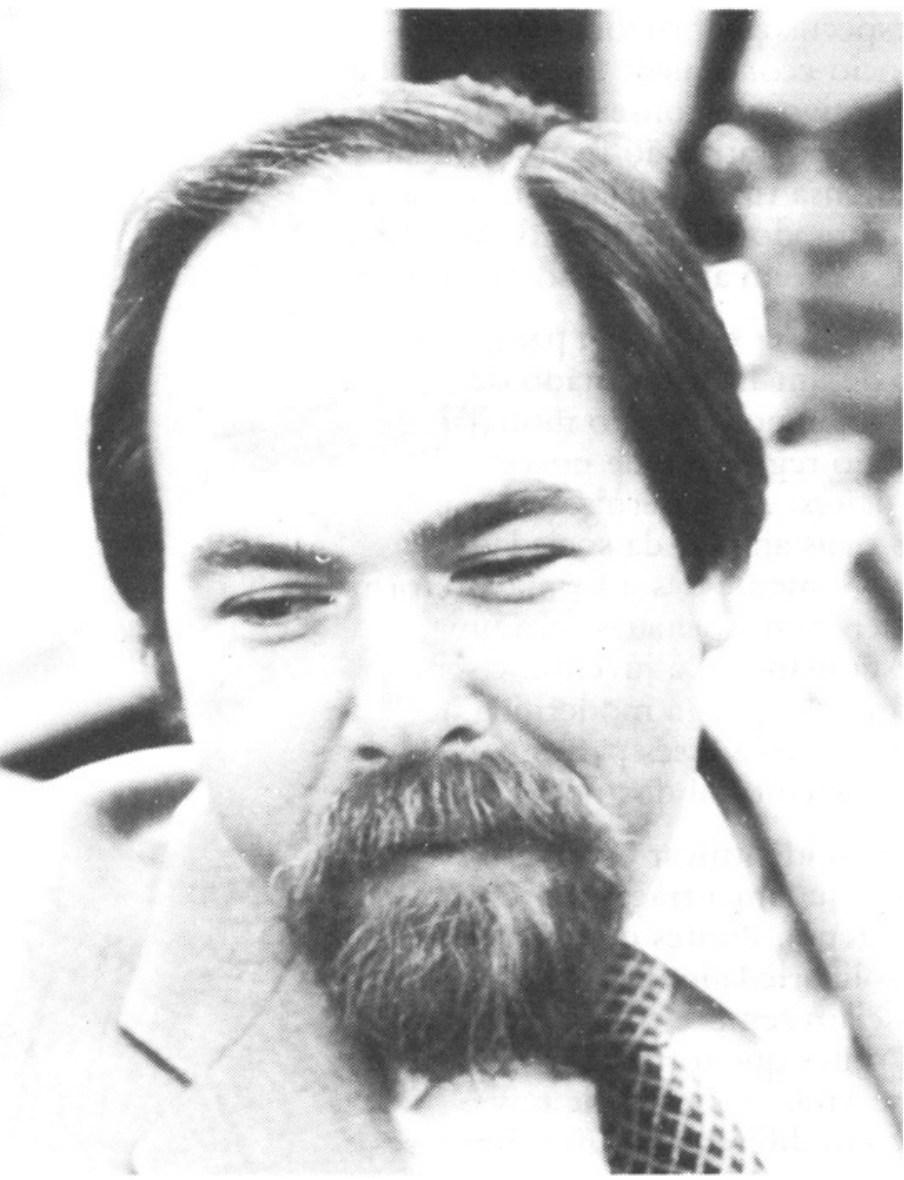

universidades e especialmente em nossas unidades de pesquisa:

Economia das Mudanças

Tecnológicas em Lyon e o

Programa de Política e

Administração em Ciência e

Tecnologia em São Paulo. As

trajetórias tecnológicas e as

estratégias industriais, as formas

de organização diante da

automação, a dinâmica do

trabalho perante as novas

tecnologias e a economia

industrial do desenvolvimento

constituem temas de grande

interesse comum. Este grande

interesse permitiu que os milhares de quilômetros que nos separam fossem reduzidos a um traço de união, um hífen, que unifica nossos grupos de pesquisa.

Todo este passado, caros colegas, nos revela a existência de pontes solidamente construídas que nos permitem meditar, náo somente sobre os resultados já obtidos, mas também a respeito do futuro destas relaçōes.

As transformações geopolíticas mundiais, os novos blocos geoeconômicos, os desafios tecnológicos e os impasses do desenvolvimento exigem dos países intermediários uma estratégia de inserção neste novo contexto mundial. A união dos países pós-industrializados, em torno de políticas econômicas harmônicas, oferece possibilidades de ação consideráveis, mas implica também em sérios riscos que devemos evitar. As subvençóes à agricultura e as novas normas de regulamentaçáo da propriedade intelectual, por exemplo, não podem mais ser ignoradas pelos países intermediários. $\mathrm{O}$ Brasil e vários países da América Latina protegeram certas ilhotas de modernização na pesquisa e na produção. A pesquisa agrícola oferece resultados consideráveis; a produção recupera a competitividade, o que permite um aumento visível das exportaçôes.

Por outro lado, os juros da dívida, pagos na medida das possibilidades, provocam uma permanente transferência de capitais do Sul para o Norte.

Para um país como o Brasil, a liberalização econômica ou o protecionismo do passado constituem exemplos de opçóes por demais simples $\mathrm{e}$ inadequadas a uma economia complexa e dualista. A busca de uma estratégia de inovação é prioritária, mas se as ilhotas de modernizaçáo representam pontos fortes, o País sofre também as conseqüências de profundas desigualdades sócio-econômicas $e$ regionais. Indices de rentabilidade muito elevados coexistem com uma 
fraca propensão ao investimento. A especulação provoca taxas de inflação consideráveis. Os impasses sócio-econômicos tornam difícil a ação do Estado no sentido de tornar efetivo um consenso nacional, que volta a ser possível em função da democratização reencontrada. Esta última, acompanhada por uma intensa turbulểncia econômica e pelo caos monetário, poderá incitar, de modo contraditório, os novos centros de decisão, em nível mundial, a darem as costas ao nosso país.

Caros colegas, uma nova estratégia deverá ser elaborada para os anos 90. Deverá basear-se na reconstrução de um Estado dotado de credibilidade, em um projeto de reinserção no contexto mundial, de reduçáo das desigualdades, de integraçáo regional e de novos mecanismos de colaboração entre os países. A modernização tecnológica deverá atingir as camadas mais amplas da sociedade levando a uma redução das diferenças. Somente desta forma a reforma conservadora da mudança técnica poderá transformar-se em uma verdadeira revolução tecnológica. Desta maneira, a juventude será preservada nós países periféricos em marcha para a modernidade, única alternativa capaz de garantir um futuro a esses países, respeitando igualmente a rica diversidade cultural dos povos.

Isto, caros colegas e amigos, permite-nos identificar os desafios do presente e do futuro. Desafios que nos ajudam a traçar um esboço das novas pontes cuja construçăo se faz urgente. Pontes que têm por cimento o universalismo e por aço a solidariedade. Pontes que permitiráo que os problemas morais sejam sempre tratados de maneira global e por estradas de duas mãos. Pontes que tornarão possível uma nova e mais ampla colaboração, favorecendo a adoção de novas soluções para os impasses vivenciados em diferentes países, impasses que ameaçam náo apenas o futuro desses países, mas toda a sociedade humana.

O desafio das ciências e da tecnologia, bem como o fato de que esta cerimônia ocorra sob o signo do Bicentenário da Revolução Francesa, nos recordam a obra do bispo nascido na Lorena que dedicou sua vida a uma atividade humanitária de inúmeras facetas. Sob o pseudônimo de amigo dos homens de todas as cores, ele assumiu a defesa das minorias, das vítimas de erros judiciários e das naçóes menos favorecidas contra as grandes potências.

Trata-se do abade Grégoire que, em 29 de setembro de 1794, exortou a nação a aumentar a soma dos conhecimentos e o número dos conhecimentos. Coube a ele aceitar o desafio de esclarecer a ignorância que nada conhece e a pobreza que não tem meios de conhecer.

Senhor presidente, senhor chanceler, caros amigos, encerro esta alocução, expressando a honra que me é concedida através da atribuição do título de Doutor Honoris Causa. É sobretudo um privilégio recebê-lo juntamente com os professores Gïnther Mieth, Colin Lucas e com o escritor e cenarista Jorge Semprún. A eles, que dedicaram suas vidas à cultura de maneira exemplar e engajada, apresento aqui minhas homenagens.

Muito obrigado.

Jacques Marcovitch, professor da FEA/USP e diretor do IEA. 